\title{
Routinization, work characteristics and their relationships with creative and proactive behaviors
}

\author{
SANDRA OHLY ${ }^{1 *}$, SABINE SONNENTAG ${ }^{2}$ \\ AND FRANZISKA PLUNTKE ${ }^{1}$ \\ ${ }^{1}$ Technical University of Braunschweig, Spielmannstrasse, Braunschweig, Germany \\ ${ }^{2}$ University of Konstanz, Konstanz, Germany
}

Summary Researchers have claimed that routinization hinders creativity. However, empirical evidence for this assumption is sparse. In this study, we argue that routinization may be beneficial for creativity and related behavior due to available resources that can be used to develop new ideas while working. We examine the relationship between routinization and four work character istics (job control, job complexity, time pressure, and supervisor support) on the one hand and a range of creative and proactive behaviors on the other hand in a randomly selected sample of 278 employees of a German high tech company. Regression analyses reveal that in addition to work characteristics, routinization is generally positively related to creative and proactive behaviors. Ways to enhance routinization and thereby creative and proactive behaviors are discussed.

\section{Introduction}

Routinization has often been assumed to be detrimental to individual creativity (Ford \& Gioia, 2000) and organizational innovation (Pierce \& Delbecq, 1977), two outcomes highly valued in today's globalized economy (Anderson, De Dreu, \& Nijstad, 2004). However, only a few studies have adequately tested this assumption. Moreover, a recent study has shown that routinization might not always be detrimental (Gilson, Mathieu, Shalley, \& Ruddy, in press). More specifically, when taking into account that routinization spares time and cognitive resources, the negative view of routinization for individual creativity can be challenged. The purpose of this study is to discuss how routinization might be associated with creativity and innovation and to provide an empirical test of the relationship between routinization and more traditional work characteristics such as job control, job complexity, supervisor support, and time pressure with a range of creative and proactive behaviors.

\footnotetext{
* Correspondence to: Sandra Ohly, Technical University of Braunschweig, Spielmannstrasse 19, 38092, Braunschweig, Germany.

E mail: s.ohly@tu bs.de
} 


\section{Creative and Proactive Behaviors in Organizations}

Employees' creative and proactive behaviors are thought to be beneficial for organizations (Unsworth \& Parker, 2003). Four different creative and proactive behaviors will be examined in this study: creativity, innovation, personal initiative, and submitting ideas to a formal suggestion system. Creativity is the production of novel and useful ideas (Amabile, 1988), and innovation is the implementation of novel and useful ideas (Amabile, 1988; West, 2002). Behavior that is self-started and change-oriented in order to enhance personal or organizational effectiveness is called proactive (Unsworth \& Parker, 2003). Personal initiative is a specific form of proactive behavior that is defined as 'a behavior syndrome resulting in an individual's taking an active and self-starting approach to work and going beyond what is formally required in a given job' (Frese, Kring, Soose, \& Zempel, 1996, p. 38). Personal initiative includes behavior characterized by a long-term focus and persistence, and that is goal-directed, self-starting, and consistent with the organizational goals.

A formal suggestion system is 'an administrative procedure for collection, judging, and compensating ideas which are conceived by employees of the organization' (Ekvall, 1971, p. 13). Submitting ideas to such a formal suggestion system is sometimes seen as a form of initiative on the side of the employee because it requires extra effort, and sometimes as a form of innovation (Frese, Teng, \& Wijnen, 1999). Submitting ideas can also be seen as the outcome of proactive behavior and creative ideas (Frese et al., 1999). Indeed, in recent studies, the number of suggestions made was positively related to proactive and creative behaviors (Axtell, Holman, Unsworth, Wall, \& Waterson, 2000; Clegg, Unsworth, Epitropaki, \& Parker, 2002; Frese et al., 1999). In this study, submitting ideas is seen as both a creative and proactive behavior. We will test the relationships of routinization and traditional work characteristics with these four creative and proactive behaviors: creativity, innovation, personal initiative, and suggesting ideas in a formal suggestion system.

\section{Routinization}

Routinization refers to automaticity in behavior. Features of automaticity include unintentionality, uncontrollability, lack of awareness, and efficiency (Bargh, 1994). Routinization develops through repeated execution of a behavior (Betsch, Haberich, Glöckner, Haar, \& Fiedler, 2001; Ouellette \& Wood, 1998; Weiss \& Ilgen, 1985) or, specifically in case of a skill, through practice (Anderson, 2000; VanLehn, 1996). During the skill acquisition process, performance becomes faster (Wickens \& Hollands, 2000), mental resources are freed, the attentional load on the person is reduced (Kanfer \& Ackerman, 1989), and performance requires progressively less conscious processing (Norman \& Bobrow, 1975). Research on habits and automaticity gives important insights into the role of routinization in behavior regulation (Bargh \& Barndollar, 1996; Ouellette \& Wood, 1998). Through frequent and consistent coactivation (Shiffrin \& Schneider, 1977), representations of environmental features become associated with goals and behavior. As a result, environmental features can automatically trigger a behavior without a conscious decision to execute the behavior. Moreover, single behavior steps are not consciously chosen but form a pattern that is stored in memory (Bargh \& Barndollar, 1996). Once the behavior execution is triggered, the whole pattern will be executed. Empirical evidence suggests that primed goals can automatically elicit behavior without conscious attention (Aarts \& Dijksterhuis, 2000), and frequency of prior behavior execution is a stronger predictor for future behavior if the environment is stable than when the environment is unstable 
(Ouellette \& Wood, 1998). These results stress the role of environmental features that might act as triggers to elicit behavior (e.g., work behavior).

In the work setting, the tasks individuals need to accomplish have the same function as goals in nonwork contexts (Frese \& Zapf, 1994). When a task is presented to an individual, and the task is familiar because it has been accomplished repeatedly in the past, environmental features will automatically activate the necessary behavioral pattern. That is, the way to solve the task is not consciously chosen each time the task is completed. For example, when a network administrator has to give technical support for the computer system, the sight of an error message on the computer screen automatically elicits the appropriate cognition and behavior to solve the computer error. For the automatic elicitation of behavior to occur, the same strategy must have repeatedly and predictably led to task accomplishment. In that sense, routinization is a psychological result of repetitive and predictable tasks (Perrow, 1970). Traditionally, routinization is treated as a feature of an employee's job or of the technology of an organization (Perrow, 1970; Price \& Mueller, 1981) and is seen as the opposite of complexity (Baba \& Jamal, 1991). It is important to note that in our conceptualization routinization is not the opposite of complexity. Also in more complex jobs, some activities are executed repeatedly and predictably lead to the same result each time they are performed. The network administrator has a complex job but nevertheless shows routinization in some work tasks. The relationship between routinization as automaticity in behavior and creativity and related behavior is discussed below.

\section{Relationship Between Routinization and Creative and Proactive Behaviors}

There are two contradicting views on how routinization might affect creativity and innovation. One the one hand, routines and creative actions are seen as competitors (Ford \& Gioia, 2000). On the other hand, routinization might be beneficial for creativity because it frees cognitive resources to think about other aspects of work; also, time is saved when a routine is used. We will now discuss each of these two perspectives in detail.

Following the rationale of routinization as hindering creativity in organizations (Ford \& Gioia, 2000), one can argue that routinization will narrow the range of behavior that organizational members will enact in familiar settings. Thus, creative actions will only emerge when their consequences are relatively more desirable than the consequences of routines. The routines are attractive due to their past success, relative ease and certainty. The potential negative consequences of routines are vividly expressed by the following quote: 'Associative thinking is based on habit, or following set routines, adherence to rules and disciplinary boundaries, and use of rationality and logic. The problem solver working within established methods or procedures is likely to generate conventional solutions' (Scott \& Bruce, 1994, p. 587). Although the idea that routines at work are detrimental for creativity is widespread (Anderson et al., 2004; Cardinal, 2001; De Jong \& Kemp, 2003; West, 2002), empirical evidence for this argument is sparse.

Because mental resources are freed when a behavior is practiced often, it is possible that routinization enhances creativity by enabling employees to think more about their work. When task cues automatically trigger the behavior to work on the task, no conscious decision about what to do is needed anymore; so, employees are able to think about other aspects of work. In this way, problems at work might be discovered and new ways of solving these problems can be thought through. Also, performance on tasks that have been practiced gets faster (Kanfer \& Ackerman, 1989). As a result, employees have time available to think about the task and to develop new ideas, a prerequisite for creativity. Therefore, routinization may be positively related to creativity. The idea that resources are 
spared during practice and can be used for other tasks is consistent with the resource allocation theory (Kanfer \& Ackerman, 1989). Most relevant will be the routinization of behavior in tasks that are frequently accomplished. When a task is performed frequently, a substantial amount of time will be saved, and the amount of cognitive resources spared will be large enough to be invested in other behavior. In contrast, the benefits of routinization of infrequent or unimportant tasks will be limited. Therefore, we will concentrate on frequently executed and important work tasks in this study.

The two contrasting views about routinization and creative behavior have not yet been tested. To our knowledge, only a few studies so far have explicitly examined the proposed negative relationship between routinization and creativity. In each of these studies, routinization was not directly measured; instead, some proxy variables were used.

For example, Gilson \& Shalley (2004) argued that organizational tenure leads to skills and knowledge that are beneficial to creativity but at the same time leads to a tendency to adhere to strict routines rather than to seek new approaches to work. Therefore, individuals with an intermediate level of organizational tenure are expected to have enough skills and knowledge without being too constricted by routines. Thus, they are expected to be most creative. Analysis showed that selfmanaged teams with an intermediate level of organizational tenure were rated as engaging more in the creative process than teams with low or very high organizational tenure.

An experimental study examined the effect of showing model solutions (routine or creative) and expected evaluation (informal or controlling) on the creativity of the solution of an in-basket exercise (Shalley \& Perry-Smith, 2001). Showing a routine solution was expected to be detrimental to creativity because it activates a cognitive script that participants follow even when told not to. Results revealed that showing a creative solution as a model enhanced creativity, but contrary to what was expected, showing a routine model solution did not reduce creativity, compared to a control group that was not shown any sample solutions. Thus, the expectation that routine models are detrimental to creativity was not confirmed.

In a study on the antecedents of innovative behavior of research and development (R\&D) employees, managers rated employees with routine jobs (more structured, routine, and granting less autonomy) as showing less innovative behavior than employees whose jobs were less routine (Scott \& Bruce, 1994). Similarly, job complexity, seen by some researchers (e. g., Baba \& Jamal, 1991) as the opposite of routine, was positively related to a number of creative and innovative outcomes (Oldham \& Cummings, 1996; Tierney \& Farmer, 2002). As noted above, also in complex jobs, routinization can develop.

Focusing on the organizational level of analysis, it has often been proposed that formalization inhibits organizational innovation (Aiken, Bacharach, \& French, 1980; Pierce \& Delbecq, 1977). Formalization, defined as 'the degree to which a codified body of rules, procedures or behavior prescriptions is developed to handle decisions and work processing' (Pierce \& Delbecq, 1977, p. 31), is expected to govern the way that employees execute their work tasks so that modes of behavior become rigid and creative problemsolving becomes less likely (Pierce \& Delbecq, 1977). Employees are expected to rely on the rules instead of developing new patterns of behavior (Cardinal, 2001). However, empirically, the proposed negative relationship between formalization and organizational innovation has not consistently been found. Formalization was essentially unrelated to innovation in a meta-analysis based on 25 effect sizes (Damanpour, 1991). The relationship was positive in some more recent studies (Andrews \& Smith, 1996; Cardinal, 2001; Johnson, Meyer, Berkowitz, Ethington, \& Miller, 1997; Mellor \& Mathieu, 1999).

Taken together, the empirical evidence for negative relationships between routinization and creativity or innovation is sparse. Thus, following the argument presented above, when treating routinization as a psychological result of repeatedly executing the same task (automaticity in behavior), one would expect routinization to be positively related to creativity and innovation because it sets free 
cognitive resources and saves time, thereby enabling the employee to think about his or her job and find problems and develop solutions. Routinization is also expected to be positively related to personal initiative because proactivity and persistence also require resources that are more readily available when tasks are routinized. Similarly, these resources will also result in more suggestions submitted. Therefore, we expect

Hypothesis 1: Routinization will be positively associated with creativity, innovation, personal initiative and submission of ideas.

\section{Work Characteristics Predicting Creative and Proactive Behaviors}

To test if the relationship between routinization and creative and proactive behaviors holds when more traditional work characteristics are taken into account, we include job control, job complexity, time pressure, and supervisor support in this study. We expect a positive relationship between the three work characteristics job control, job complexity and supervisor support, and creative and proactive behaviors. Time pressure will have an inverted U-shape relationship with creative and proactive behaviors. These four work characteristics have been found to be related to creative and proactive behaviors in previous studies (e.g., Oldham \& Cummings, 1996; Scott \& Bruce, 1994; Tierney \& Farmer, 2002) and give starting points to enhance these desirable outcomes in organizations. For this reason, they are worth studying.

Job control, job complexity, and supervisor support are expected to be beneficial for creativity and innovation because they promote intrinsic motivation (Amabile, 1988; Oldham \& Cummings, 1996; Zhou, 1998) and increase knowledge, all of which are expected to enhance creativity and innovation (Unsworth \& Parker, 2003). When employees are intrinsically motivated to do their work and have the necessary knowledge to detect problems and flaws in their work, they are more likely to come up with novel and useful ideas and are more ready to implement them. Having control over how to execute a task makes asking others for permission or searching for allies obsolete. Asking for permission or searching for allies could hinder implementation. Thus, job control is also beneficial for innovation. Job complexity makes innovation more likely because employees in more complex jobs tend to see it as their task to improve working procedures (Frese et al., 1999). Both job control and job complexity also enable employees to experiment with new ideas and to develop them while working before submitting them to the suggestion system. The likelihood that an idea will be developed in sufficient detail is increased, making it more likely that an employee submits the idea. If an employee does not have a chance to develop an idea while working, the idea may be forgotten or never be detailed enough to be submitted. Job control and job complexity will also be positively related to personal initiative because these work characteristics enhance the felt responsibility for solving problems (Frese et al., 1996). Because in our conceptualization routinization and job complexity are not polar opposites, the expectation that both complexity and routinization will be beneficial for creative and proactive behaviors is not contradictory.

Supervisor support can promote employees' feeling of self-determination and thereby also increase personal initiative (Oldham \& Cummings, 1996). In addition, supervisor support for specific employee behavior indicates what is valued in the organization (Baer \& Oldham, in press). A supervisor supporting creative and proactive behaviors makes clear that this is a desired behavior in the organization, thus making it more likely that employees exhibit the behavior.

In studies testing the relationships of work characteristics with creative and proactive behaviors, job complexity and supervisor support were found to be positively related to supervisor rated creativity and 
to number of patents, but not to successfully making suggestions (Oldham \& Cummings, 1996). Quality of leader-member relationship, an indicator similar to supervisor support, was positively related to supervisor ratings of innovative behavior (Scott \& Bruce, 1994) and to a range of creative outcomes (Tierney et al., 1999). Supervisor support (and job complexity) predicted creative selfefficacy and creative performance (Tierney \& Farmer, 2002) and general work support was positively related to creative performance (Madjar, Oldham, \& Pratt, 2002). Thus, supervisor support seems to be an important predictor for a range of creative and proactive behaviors.

There is some empirical support for the proposed positive relationships of job control with creative and proactive behaviors. 'Freedom' was listed by the majority of scientists to be a major factor involved in creative incidents (Amabile, 1988). Task autonomy was a necessary condition for creative performance (Shalley, 1991; Zhou, 1998) and autonomy was positively related to innovative behavior of service firm employees (De Jong \& Kemp, 2003). Job control and job complexity promote personal initiative (Frese \& Fay, 2001).

Amabile (1988) has specified 'pressure' as a feature of the work environment that both promotes and inhibits creativity. She notes that a balanced amount of time pressure might be most helpful to increase creativity. Recent research (Baer \& Oldham, in press; Janssen, 2001) has suggested an inverted U-shape relationship between time pressure and creativity or innovation, disagreeing with the assumption of a negative relationship between time pressure and creative outcomes (Amabile et al., 2003; Andrews \& Smith, 1996). Following the rationale of the activation theory (Gardner, 1986; Scott, 1966), increasingtime pressure increases activation, which then affects cognitive and behavioral responses. When time pressure and experienced activation are at intermediate levels, individuals are optimally stimulated and favorable responses, such as creative solutions to problems, are more likely to occur. But when time pressure is high or low, less positive responses are expected. Accordingly, Janssen (2001) found a curvilinear relationship between time pressure (operationalized as high job demands) and supervisorrated innovative performance of management employees. In another study, the expected curvilinear relationship of time pressure only occurred under high work support or high non-work support (Baer \& Oldham, in press). Following the rationale of activation theory, we will test the proposed curvilinear relationship between time pressure and creativity, innovation, personal initiative, and submission of ideas.

Taken together, based on previous studies and on the reasoning discussed above, we formulate the following hypotheses:

Hypothesis 2: Job control, job complexity, and supervisor support will have a positive relationship with creativity, innovation, personal initiative, and submission of ideas.

Hypothesis 3: Time pressure will have a curvilinear relationship on creative and proactive behaviors: An intermediate level of time pressure will be related to the highest level of creativity, innovation, personal initiative, and submission of ideas.

\section{Organizational Context}

We conducted our study in a large internationally operating high-technology company in Germany. This company has about 3000 employees at the site in study. The company's leadership system is based on communication with and commitment of the employees, expressed in regular appraisal interviews and goal-setting. Managerial employees in the company are paid according to 
individually-agreed salaries which also include profit-sharing, but all other personnel are paid according to collectively agreed salaries and do not participate in profit-sharing.

The organizational suggestion system has been effective for several decades and functions similarly to suggestion systems in other companies (see Frese et al., 1999). Traditionally, the system targeted suggestions by production workers, but at the time of the study (in 2004) it was in the process of being reformed to more strongly address the ideas of other personnel. Of the 1000 suggestions made in 2001 and 2002, approximately half were realized. A total of 600000 Euros (approximately $\$ 580000$ at that time) were paid as benefits to the employees who submitted suggestions that benefited the organization as judged by several experts in the organization. Because the number of suggestions was declining and low compared to other sites of the organization, the manager of the organizational suggestion system was interested in factors contributing to suggestions. Thus, this study was undertaken.

\section{Method}

\section{Sample}

Participants were 302 employees. Questionnaires were sent to 675 randomly selected employees of the company, and 302 employees completed the questionnaire, representing a response rate of 44.74 per cent. Of the 302 individuals, 238 were men (79.3 per cent). Respondents worked in very different areas of operation, including production (10 per cent), R \& D (33 per cent), sales and marketing ( 26 per cent), and others ( 31 per cent). Most of the respondents were employed in business areas dealing with public transport. The modal age category was 36 to 45 years and the modal length of work experience category was 6 to 15 years. Seventy-three per cent of individuals in the sample had a college degree and 17.0 per cent held a leadership position. Due to missing values in some of the main study variables, sample size for the main analyses was reduced to 278 .

\section{Measures}

To minimize common method bias, routinization, work characteristics, and creative and proactive behaviors were measured on different levels of specification (Podsakoff, MacKenzie, Lee, \& Podsakoff, 2003). Routinization was measured on the level of specific tasks (see below); work characteristics were assessed as stable features of jobs, and creative and proactive behaviors as the general propensity to engage in the behavior. In addition to the assessment of the main study variables, employees were also asked about their attitudes towards the suggestion system (e. g., availability of information, computerized suggestion making). However, this information offered few insights, and will thus not be reported in this paper. As previous studies have shown that demographic variables such as job experience, education, and gender are related to creative and proactive behaviors (Scott \& Bruce, 1994; Sonnentag, 2003; Tierney, Farmer, \& Graen, 1999; Zhou, 1998), we included these variables as control variables. In addition, because there were employees of different areas of operation in the sample ( R \& D, marketing and sales, production), we also controlled for area of operation.

Creativity was rated by the employees on a seven-point rating scale ranging from $1=$ 'not true' to $7=$ 'totally true' using seven items from Tierney et al. (1999). These seven-items target the amount of 
novel and useful ideas employees have at work. A sample item is 'I demonstrate originality in my work.' Cronbach's alpha for the seven-item scale was 0.92 .

Innovation was measured with six items targeting the degree that novel and useful ideas are implemented at work. Item wording was based on Zhou and George (2001). A sample item is 'I implement my new ideas to improve performance.' Employees rated their innovation on a seven-point scale ranging from $1=$ 'not true' to $7=$ 'totally true.' Cronbach's alpha was 0.90 .

Personal initiative was measured with seven items (Frese, Fay, Hilburger, Leng, \& Tag, 1997) on a five-point scale ranging from $1=$ 'not true' to $5=$ 'totally true.' A sample item is 'I actively attack problems.' Cronbach's alpha was 0.77 .

Because creativity, innovation, and personal initiative represent related constructs and are significantly correlated (with correlations ranging between $r=0.46$ and $r=0.64$; Table 1), we conducted a Confirmatory Factor Analysis to determine whether the 20 items of three scales represent separate constructs. Comparisons between the one-factor, the two-factor (creativity and innovation loading on one factor), and the three-factor-solution were made (a) using the chi-square difference test and (b) comparing values of the CFI. This specific two-factor model was chosen as a plausible alternative model because creativity and innovation are often seen as closely related, representing separate steps in a process of first developing ideas and then implementing them (Rank, Pace, \& Frese, 2004). The three-factor model showed a better fit than the two-factor model, $\Delta \chi^{2}(2, N=285)=459.63$ $(p<0.001)$ and $\Delta \mathrm{CFI}=0.09$, and than the one-factor model, $\Delta \chi^{2}(3, N=285)=991.31(p<0.001)$ and $\Delta \mathrm{CFI}=0.19$. Additionally, the RMSEA as an index of parsimonious model fit was lower for the three-factor model $($ RMSEA $=0.083)$ than for the two-factor model $($ RMSEA $=0.126)$ and the onefactor model (RMSEA $=0.162$ ). Thus, creativity, innovation, and personal initiative represent distinct constructs.

The number of suggestions made was collected in two ways. First, employees reported the numbers of suggestions that they made in the three years prior to data collection in the questionnaire. Second, we assessed an objective measure of the number of suggestions made. Specifically, respondents were asked to send in a separate sheet with their personnel number and the code of the questionnaire to enable us to match the number of suggestions made from the company's data base to the questionnaire data. After confidentiality was ensured, 239 participants agreed to send their personnel number. Of these, 125 did not submit suggestions in the 3-years prior to the study. Thirtyeight submitted one idea, 19 submitted 2 ideas, 9 submitted 3 ideas, and a declining number of study participants submitted four, five or more ideas (up to 21 ideas). Of 55 study participants, the number of suggestions made could not be matched to the questionnaire data due to the missing personnel number. Because the sample size for the self-reported number of suggestions was much higher, and both measures were highly correlated $(r=0.81 ; p<0.001)$, we used the self-reported number of suggestions made for later analyses. We also gathered the number of suggestions rewarded by the organization from the organizational database. Data was available for this variable from 217 study participants. For correlation analysis we dichotomized the number of suggestions made as $0=$ 'no suggestions made' and $1=$ ' 1 or more suggestion made' because this variable was highly skewed. For the test of the hypothesis, this dichotomization was unnecessary because of the application of the negative binomial regression.

Routinization was measured with five items targeting the degree of behavioral automaticity. Respective items were taken from the habit strength scale (Verplanken \& Orbell, 2003). To ensure that the feeling of routinization targeted a specific behavior, individuals first wrote down three frequently accomplished tasks and then chose the most important one for their job. The tasks listed by employees working in marketing and sales can roughly be subsumed in the following categories: Dealing with documentation (e.g., 'to archive files'), submitting offers, dealing with customers, making calculations, and attending meetings. Examples of tasks listed by employees in research and 


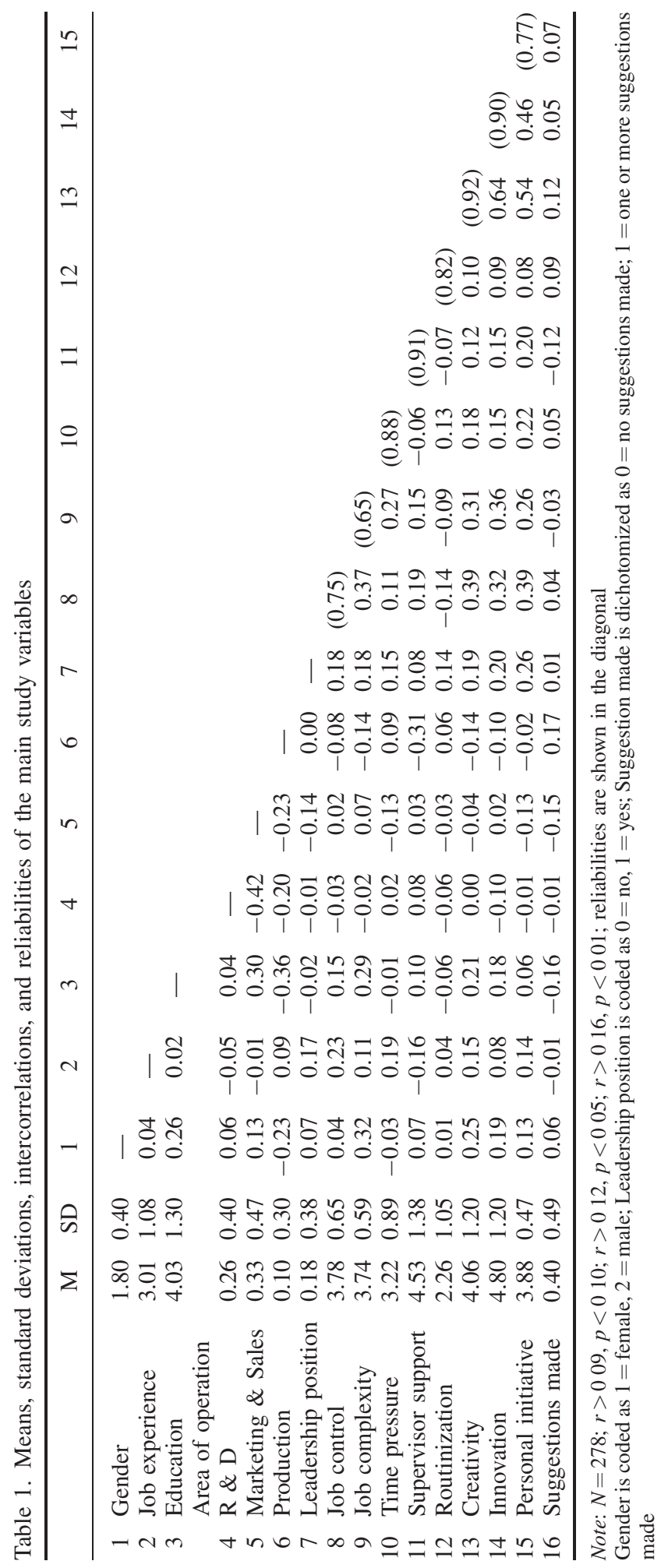


development fall in the following categories: Developing software, dealing with documents and spreadsheets, handling emails, and interacting with subordinates. Tasks listed by employees in production can be summarized in the following categories: Technical tasks (e.g., 'to solder,' 'assembly'), planning and organizing, quality check, and dealing with subordinates. For each area of operation there were also activities that cannot be subsumed into one of the categories. Nonetheless, from the activities listed it becomes clear that activities in different areas of operation can all be routinized with practice. Routinization items were answered for this specific activity on a five-point scale, ranging from (1) not true to (5) totally true. A sample item is 'Behavior $\mathrm{X}$ is something... I do automatically.' Cronbach's alpha was 0.82 .

\section{Work characteristics}

Three scales developed by Semmer (1984) and widely used in German-speaking countries (cf. Frese et al., 1996; Grebner, Semmer, \& Elfering, 2005; Zapf, 1993) were used to measure job control, job complexity, and time pressure. The scales were developed to assess work characteristics independently of individual performance and individual level of work experience (Semmer \& Zapf, 1989). These self-reported work characteristics show medium to high correlations with expert ratings of the job (Semmer, Zapf, \& Dunckel, 1999). All items were answered on a five-point scale. Anchoring of the items of these scales differs and reflects either frequencies (e. g., $1=$ 'practically never' to $5=$ 'several times a week') or intensities (e. g., $1=$ 'very low' to $5=$ 'very high'). Specifically, job control was assessed with five items that referred to the degree an individual can influence the methods of doing his or her job. A sample item is: 'Can you influence the way of how you accomplish your tasks?' Cronbach's alpha was 0.75 . Job complexity was measured with five items targeting the extent to which the job calls for planning and difficult decisions. A sample item is: 'How often do you get tasks that are difficult to accomplish?' Cronbach's alpha was 0.65. Time pressure was measured with four items that referred to a high quantitative work load. Originally, the scale consists of five items, but the item asking if employees are late for breaks had to be omitted due to concerns of the workers' committee. A sample item is: 'How often do you work under time pressure?' Cronbach's alpha was 0.88 .

Supervisor support was measured with eight items from Oldham and Cummings (1996). These items assess the extent to which a supervisor encourages employee participation, keeps the employees informed, and rewards good performance. Items were rated on a seven-point scale ranging from (1) not true to (7) totally true. A sample item is 'My supervisor helps me solving work-related problems.' Cronbach's alpha was 0.91 .

We tested the fit of a five-factor model with the 27 items representing routinization, job control, job complexity, time pressure, and supervisor support. The resulting model showed a good fit $(\mathrm{CFI}=0.93$, $\left.\chi^{2}=564.89, \mathrm{df}=314, \mathrm{RMSEA}=0.053\right)$.

\section{Demographic variables}

Leadership position was measured with one item asking if the respondent has disciplinary responsibilities. Gender was measured with one item. Education was measured by asking for the highest degree reached. The rating scale was $1=$ none, $2=$ apprenticeship completed, $3=$ master craftsman, $4=$ vocational school or $5=$ master's degree. Job experience was measured with one item asking for the number of years in the job. Area of operation was measured with one item. The rating scale was $1=$ research and development, $2=$ marketing and sales, $3=$ production, and $4=$ others. Area of operation was dummy-coded into three variables indicating the membership in the particular group $(1=$ yes, $0=$ no $)$. 


\section{Results}

Table 1 shows means, standard deviations, and zero-order correlations of the main study variables. Multiple regressions using ordinary least square estimation were used to test the hypotheses regarding creativity, innovation, and personal initiative. Multiple regression analysis allows for the simultaneous testing of the predictors and for the inclusion of control variables. As the number of suggestions made represented a form of count data, ordinary least square estimation was not appropriate due to the violation of several assumptions for this analysis (e.g., normal distribution, heteroscasdicity, c.f. Gardner, Mulvey, \& Shaw, 1995; Tierney, Farmer, \& Graen, 1999). Therefore, negative binomial regressions in LIMDEP were used to test the hypotheses. Negative binomial regression is a special form of Poisson regression that models the over-dispersion of count data when the variance is greater than assumed under a Poisson distribution (Gardner et al., 1995). Negative binomial regressions produce parameter estimates comparable to regression weights of the ordinary least square regression. Likelihood ratio tests were used to test the incremental model fit of models including additional predictors. Additionally, it has been proposed that Pseudo $\mathrm{R}^{2}$ can be computed comparing the likelihood function of a given model to that of an intercept-only model (Dietz, Robinson, Folger, Baron, \& Schulz, 2003). However, this approach may also be criticized because the likelihood function of the intercept-only model of the negative binomial regression cannot be calculated non-iteratively (the maximum likelihood estimation is used for estimation of the dispersion parameter). A solution to this problem could be the use of log likelihood estimations of a Poisson regression (without dispersion parameter) as a benchmark for the negative binomial models containing the proposed predictors. It should be noted, however, that this approach confuses the improvement in the likelihood function resulting from the inclusion of the predictors with that from the improvement of the modeling of the over-dispersion. To solve this problem, we report the pseudo $\mathrm{R}^{2}$ calculated in Poisson regressions. Aside from that we rely on the parameter estimates from the negative binomial regressions.

Results for the test of Hypotheses 1 to 3 regarding creativity, innovation, and personal initiative can be seen in Table 2. The control variables job experience, education, gender, leadership position, and area of operation (dummy-coded) were entered in the first step, followed by work characteristics. The squared term of time pressure was entered next, testing for the proposed curvilinear relationship with the creative or proactive behaviors. In the fourth step, routinization was entered as predictor to test Hypothesis 1.

For creativity, the control variables explained 15 per cent of the variance in the first step. Work characteristics entered in the next steps explained an additional 11 per cent of the variance. The only significant predictor was job control. Job complexity and supervisor support were not related to creativity. A similar picture emerged for innovation. The work characteristics explained an additional 11 per cent of the variance, in addition to the 13 per cent explained by the control variables. Job control and job complexity emerged as significant predictors. Again, supervisor support was not related to the outcome variable. For personal initiative, the work characteristics explained an additional 14 per cent of the variance, in addition to the 12 per cent explained by the control variables. Job control, time pressure and supervisor support were significant predictors. Thus, Hypothesis 2 was partially supported for creativity, innovation, and personal initiative.

Squared time pressure, entered in the third step, explained an additional 2 and 3 per cent of the variance in creativity and innovation, respectively. For personal initiative, including squared time pressure as a predictor did not improve the prediction. The form of the relationship between time pressure and creativity, innovation, and personal initiative is displayed in Figure 1, plotted according to the recommendations given by Cohen, Cohen, West and Aiken (2003). It can be seen that creativity and innovation were highest when time pressure was one standard deviation above the mean level of time 
Table 2. Predicting creativity, innovation and personal initiative

\begin{tabular}{|c|c|c|c|c|c|c|c|c|c|}
\hline & \multicolumn{3}{|c|}{ Creativity } & \multicolumn{3}{|c|}{ Innovation } & \multicolumn{3}{|c|}{ Personal initiative } \\
\hline & $\mathrm{R}^{2}$ & $\Delta \mathrm{R}^{2}$ & $\beta$ & $\mathrm{R}^{2}$ & $\Delta \mathrm{R}^{2}$ & $\beta$ & $\mathrm{R}^{2}$ & $\Delta \mathrm{R}^{2}$ & $\beta$ \\
\hline Step 1: Control variables & $0.15^{* *}$ & $0.15^{* *}$ & & $0.13^{* *}$ & $0.13^{* *}$ & & $0.12^{* *}$ & $0.12^{* *}$ & \\
\hline Job experience & & & 0.02 & & & 0.05 & & & 0.04 \\
\hline Education & & & $0.10^{+}$ & & & 0.09 & & & 0.01 \\
\hline Gender & & & $0.15^{*}$ & & & 0.07 & & & $0.11^{+}$ \\
\hline Leadership position & & & 0.09 & & & $0.12^{*}$ & & & $0.11^{*}$ \\
\hline $\mathrm{R} \& \mathrm{D}$ & & & $0.14^{*}$ & & & 0.10 & & & $0.20^{* *}$ \\
\hline Production & & & 0.09 & & & 0.08 & & & 0.01 \\
\hline Marketing\& Sales & & & 0.06 & & & $0.14^{*}$ & & & 0.09 \\
\hline Step 2: Work characteristics & $0.26^{* *}$ & $0.11^{* *}$ & & $0.23^{* *}$ & $0.11^{* *}$ & & $0.25^{* *}$ & $0.14^{* *}$ & \\
\hline Time pressure & & & 0.08 & & & 0.03 & & & $0.12^{*}$ \\
\hline Job control & & & $0.31^{* *}$ & & & $0.23^{* *}$ & & & $0.29^{* *}$ \\
\hline Supervisor support & & & 0.00 & & & 0.05 & & & $0.15^{*}$ \\
\hline Job complexity & & & 0.08 & & & $0.19^{* *}$ & & & 0.06 \\
\hline Step 3: Curvilinear & $0.28^{* *}$ & $0.02^{* *}$ & & $0.26^{* *}$ & $0.03^{* *}$ & & $0.26^{* *}$ & 0.00 & \\
\hline Time pressure ${ }^{2}$ & & & $0.17^{* *}$ & & & $0.17^{* *}$ & & & 0.03 \\
\hline Step 4: Routine & $0.30^{* *}$ & $0.02^{*}$ & & $0.27^{* *}$ & $0.01^{*}$ & & $0.26^{* *}$ & $0.01^{+}$ & \\
\hline Routinization & & & $0.13^{*}$ & & & $0.12^{*}$ & & & $0.09^{+}$ \\
\hline
\end{tabular}

Note: $N$ 284. ${ }^{+} p<0.10 .{ }^{*} p<0.05 .{ }^{* *} p<0.01$.

Standardized betas are reported for the final step. Leadership is coded as 0 'no leadership position', 1 'leadership position'. Gender is coded as 1 'female', 2 'male'.

pressure. Creativity and innovation are lower when time pressure was higher or lower. Personal initiative showed a linear positive trend when time pressure increased, consistent with the positive regression weight of unsquared time pressure. Thus, Hypothesis 3 was supported for creativity and innovation, but not for personal initiative.

In the final step, routinization was included as a prediction. It explained an additional 2 per cent of the variance in creativity, and 1 per cent in both innovation and personal initiative. The regression weight was significant for creativity and innovation, but failed to reach traditional levels of significance for personal initiative $(\beta=0.10, p=0.09)$. Thus, Hypothesis 1 was supported for creativity and innovation, but not for personal initiative.

Table 3 shows the predtiction of the number of suggestions made. Supervisor support emerged as significant predictor. Contrary to what was expected, supervisor support was negatively related to number of suggestions made indicating that the lower the supervisor support, the more suggestions were made. Job control, job complexity and time pressure were not significantly related to number of suggestions made. Hypothesis 2 was thus not supported for number of suggestions made. Including the squared time pressure term in the third step did not enhance the prediction. Including routinization in the fourth step enhanced the prediction significantly. However, the parameter estimate did not reach traditional levels of significance (parameter estimate $=1.81, p=0.07$ ). Thus, Hypotheses 3 was not supported for number of suggestions made.

To examine if the relationship between supervisor support and number of suggestions made is due to the fact that employees are generally dissatisfied and use the suggestion system as a means to complain, we repeated the analysis reported above using the number of suggestions that were rewarded (taken from the organizational database). Sample size for this analysis was $N=217$. The overall pattern of result remained the same. Most importantly, supervisor support was still a significant and negative 


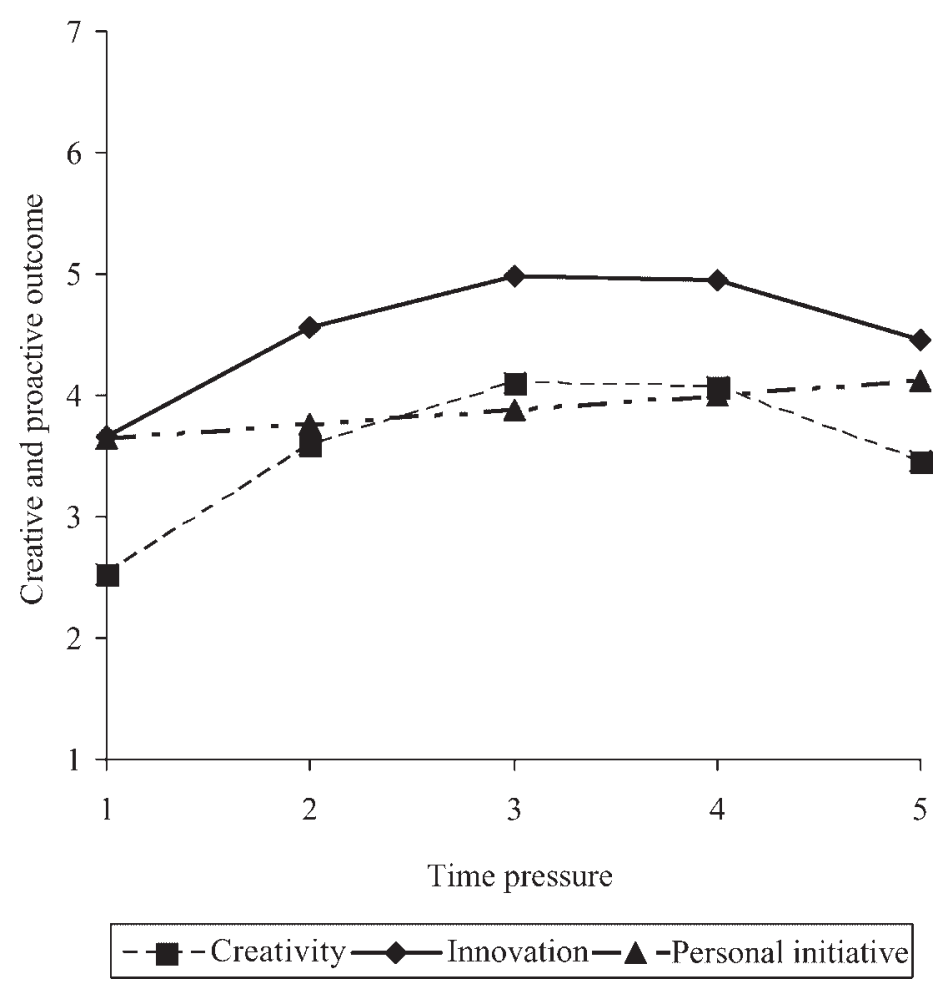

Figure 1. Relationships between time pressure and creative and proactive behaviors. Note: Creativity and innovation were measured on a seven point scale, and personal initiative was measured on a five point scale

predictor (parameter estimate $=-2.05, p=0.04$ ) indicating that employees who experienced low supervisor support also submitted high-quality suggestions. None of the other hypothesized predictors was significant.

\section{Additional analysis}

The pattern of significant predictors is very different for creativity, innovation, personal initiative, and number of suggestions made. Therefore, and in line with the conception of creativity and initiative leading to suggestions (Frese et al., 1999), we were interested whether creativity or personal initiative would best predict number of suggestions made. Thus, we included creativity and personal initiative in addition to the work characteristics. Innovation was not included as a predictor, because ideas that can be implemented by a single employee are most likely not submitted to the organizational suggestion system. Creativity was a significant predictor of number of suggestions made (parameter estimate $=2.23, p<0.05$ ), but personal initiative was not (parameter estimate $=-0.90, p>0.05$ ).

Because routinization, creativity, innovation, and personal initiative were measured by self-report, one could argue that the relationships between routinization and these variables are inflated by social desirability and other response biases. To test this possible explanation we calculated a measure of the tendency to give inflated answers. Because the tendency to give inflated answers should also manifest in an inflated number of self-reported suggestions, a new variable was calculated as the percentage of 
Table 3. Predicting number of suggestions

\begin{tabular}{|c|c|c|c|c|}
\hline & Step 1 & Step 2 & Step 3 & Step 4 \\
\hline \multicolumn{5}{|l|}{ Control variables } \\
\hline Constant & 1.40 & 0.65 & 0.65 & 1.11 \\
\hline Experience & 0.87 & 0.25 & 0.26 & 0.29 \\
\hline Education & $2.82^{* *}$ & $2.20^{*}$ & $1.99^{*}$ & $2.27^{*}$ \\
\hline Gender & $2.67^{* *}$ & $2.66^{* *}$ & $2.68^{* *}$ & $2.63^{* *}$ \\
\hline Leadership position & 0.46 & 0.50 & 0.51 & 0.45 \\
\hline Marketing \& Sales & 0.43 & 0.30 & 0.30 & 0.54 \\
\hline $\mathrm{R} \& \mathrm{D}$ & 1.00 & 1.16 & 1.18 & 1.31 \\
\hline Production & 1.27 & 0.61 & 0.61 & 0.66 \\
\hline \multicolumn{5}{|l|}{ Work characteristics } \\
\hline Job control & & 1.02 & 1.04 & 1.31 \\
\hline Time pressure & & 0.41 & 0.41 & 0.07 \\
\hline Job complexity & & 0.50 & 0.50 & 0.19 \\
\hline Supervisor support & & $2.27^{*}$ & $2.20^{*}$ & $2.33^{*}$ \\
\hline \multicolumn{5}{|l|}{ Curvilinear } \\
\hline Time pressure ${ }^{2}$ & & & 0.23 & 0.26 \\
\hline \multicolumn{5}{|l|}{ Routinization } \\
\hline Routinization & & & & $1.81^{+}$ \\
\hline Pseudo $\mathrm{R}_{\mathrm{p}}^{2}$ & 0.32 & 0.37 & 0.37 & 0.39 \\
\hline Log likelihood & 414.60 & 410.35 & 410.32 & 407.88 \\
\hline$\Delta \mathrm{LR}$ & $30.74^{*}$ & $8.50^{+}$ & 0.07 & $4.87^{*}$ \\
\hline
\end{tabular}

Note: $N$ 278. ${ }^{+} p<0.10 .{ }^{*} p<0.05 .{ }^{* *} p<0.01$.

Standardized parameter estimates are reported based on negative binomial regression. Pseudo $\mathrm{R}_{\mathrm{p}}^{2}$ is based on the standardized residuals of the Poisson regression and compares a given model with the intercept only model. Change in Likelihood Ratio assesses the significance of adding additional parameters to the model and is roughly analogous to $\Delta \mathrm{R}^{2}$.

Leadership is coded as 0 'no leadership position', 1 'leadership position'. Gender is coded as 1 'female', 2 'male'.

deviance of the self-reported number of suggestions made from the objective number of suggestions recorded in the company's data base. This new measure was used as a control variable when predicting creativity, innovation, and personal initiative. The tendency to give inflated answers was not a significant predictor in any of these analyses. Most importantly, inclusion of this control variable did not change the pattern of results reported in Table 2. For example, routinization was still a significant predictor in all these analyses. ${ }^{1}$ Thus, the relationships between routinization and creativity, innovation, and personal initiative do not seem to be inflated because of social desirability and other response biases.

\section{Discussion}

This study examined relationships between routinization and several work characteristics (job control, job complexity, supervisor support, and time pressure) and creativity, innovation, personal initiative, and submitting suggestions to the organizational suggestion system. Results revealed that routinization

\footnotetext{
${ }^{1}$ Due to space constrictions, these results are not reported in more detail. However, tables showing the results are available from the first author on request.
} 
was positively associated with creativity and innovation, but not with submitting suggestions. Job control was the strongest predictor for creativity, innovation, and personal initiative. Job complexity emerged as a positive predictor only for innovation. As predicted, time pressure had an inverted Ushaped relationship with creativity and innovation, but a linear positive relationship to personal initiative. For submitting suggestions, supervisor support was the strongest predictor. However, contrary to what was expected, the relationship was negative. Supervisor support was positively associated with higher personal initiative.

The positive relationship of routinization and creativity and innovation lends support for the assumption that routinization enables employees to develop new ideas while working and to implement them. As others have noted (Baba \& Jamal, 1991), it is necessary to distinguish different forms of routinization. Routinization in job content might have negative effects because repetition leads to boredom, but routinization on other levels, that is, routinization in specific tasks, might lead to positive outcomes, as indicated here. For creativity and innovation, routinization explained a small but significant amount of additional variance above the variance explained by more traditional predictors.

Routinization was not significantly related to number of suggestions made in the negative binomial regression. However, routinization was positively related to creativity, and creativity was positively related to number of suggestions made. Thus, routinization might not be associated directly with more suggestions. However, routinization is associated with more ideas, and more ideas are linked to making suggestions.

The strong positive relationship between job control and creativity, innovation, and personal initiative underscores the importance of granting autonomy and contradicts suggestions that high levels of control might be detrimental (Gebert, Boerner, \& Lanwehr, 2003). Employees who have control over working procedures might feel more responsible for their work (Hackman \& Oldham, 1975) and develop a more active approach to work (Frese et al., 1996). Thus, they will think more about their work, come up with new ideas, solve problems autonomously, and implement new working procedures in their work. Job complexity is thought to have similar effects (Frese et al., 1996). However, when controlling for other variables, job complexity was not significantly related to creativity and personal initiative. Only innovation was positively predicted by job complexity. Job complexity might be more important for implementing ideas than for having them because employees in more complex jobs tend to see it as their task to improve working procedures (Frese et al., 1999) which does not necessarily lead to more ideas. However, when an employee in a complex job has an idea, he or she sees it as his or her job to implement it him/herself. Taken together, it seems valid to differentiate between job control and job complexity because they show differential relationships to the outcomes of interest, instead of combining them into one index of job content or motivating potential (Frese et al., 1999; Oldham \& Cummings, 1996).

The proposed curvilinear relationship between time pressure and the outcomes was found for creativity and innovation, but not for personal initiative and number of suggestions made. The results for creativity and innovation are in line with activation theory and previous results (Baer \& Oldham, in press; Janssen, 2001). When time pressure is low, activation is expected also to be low, and development or implementation of new ideas is less likely. When time pressure is at a medium level, activation is assumed to be optimal for producing and implementing new ideas. When time pressure is very high, the activation experienced might be too high to be productive in this way. Interestingly, the relationship of time pressure and personal initiative was linear and positive. This result is in line with other studies (Fay \& Sonnentag, 2002; Sonnentag, 2003) and indicates that the optimal level of activation might be higher for tasks that involve proactivity than for tasks that involve creativity. Higher time pressure and higher activation experienced might lead employees to see a need to actively change suboptimal aspects of the work situation (Fay \& Sonnentag, 2002). In Janssen's (2001) study , curvilinear relationships of job demands emerged for supervisor-rated innovative performance but not 
for supervisor-rated job performance. Thus, higher activation might be beneficial for one form of performance outcome, but not for others. Future research will need to determine the optimal activation level for different forms of performance. Caution is needed when trying to enhance creativity primarily through time pressure. An intermediate level of time pressure is hard to determine and to implement, and high time pressure has detrimental health consequences (de Lange, Taris, Kompier, Houtman, \& Bongers, 2003). In addition, it can not be ruled out that employees with propensities to show specific levels of creative and proactive behaviors were selected or self-selected into specific jobs (cf. Parker \& Sprigg, 1999).

Routinization, job control, job complexity, and time pressure were not significantly related to number of suggestions made. The only significant predictor of number of suggestions made was supervisor support. However, this relationship was negative, contrary to what was predicted. Supervisor support was expected to be positively associated with submitting ideas because a supervisor who either actively encourages employees to submit ideas or who responds positively to suggestions was expected to make suggestions more likely. One could argue that this result is due to the possibility that employees use the suggestion system as a way to complain. However, the same pattern of findings emerged when the number of rewarded suggestions was taken as an outcome. Thus, low supervisor support is also related to employees' high-quality suggestions. The negative relationship between supervisor support and suggestions can be explained when regarding making suggestions as a way to express discontent and to voice concerns. Voice is defined as the expression of one's suggestion (LePine \& VanDyne, 1998) and is seen as a way to respond to dissatisfaction (Zhou \& George, 2001). In line with a distress-related model of innovation (Anderson, De Dreu, \& Nijstad, 2004), distress at one level of analysis affects innovation at another level. Employees who are dissatisfied with their supervisor's behavior are unlikely to voice their ideas in their work group, either because of fear to experience negative reactions or because of resignation (Van Dyne, Ang, \& Botero, 2003). Rather, they may take the opportunity that the suggestion system offers.

Supervisor support was positively related to personal initiative, but not to creativity or innovation. The significant relationship between supervisor support and personal initiative was expected because supervisor support can promote employees' feeling of self-determination (Oldham \& Cummings, 1996), which promotes personal initiative. Supervisor support was also expected to indicate which behavior is valued in the organization, and thereby make this behavior (e.g., creativity) more likely. The results do not support this expectation. The measure of supervisor support targets supervisor behavior like encouraging participation and rewarding good performance. Assessing support for creativity and innovation similar to Madjar and colleagues (2002) would have been more appropriate in this study.

Because it became clear from the pattern of results that submitting ideas is not like the other creative or proactive behaviors, future research is needed to examine the motives of employees to submit suggestions, especially when supervisor support is low. Our results suggest that the work characteristics that are related to creativity, innovation, and personal initiative are very different from those that lead to making suggestions. Specifically, job control, job complexity, time pressure, and routinization did not show any significant relationship to making suggestions. These differing results were not expected. While one could argue that the differing results are due to the differing nature of the variables (selfreport vs. objective data), the relationships of supervisor support with personal initiative (positive relationship) and supervisor support and making suggestions (negative relationship) implies that this explanation is not true. Creativity and making suggestions can be seen as a process, as the additional analysis showed that creativity was related to the number of suggestions made. Not all ideas are suitable for the suggestion system, however, and there might be barriers to submitting suggestions (Frese et al., 1999). To improve a suggestion system, it will be necessary to identify these barriers and to reduce them to make better use of employees' creativity. 


\section{Study limitations}

Some limitations in the study design must be noted. We used cross-sectional data to test our hypotheses. Therefore, no conclusion about causality can be drawn. With regard to the relationship of routinization and creative and proactive behaviors, it is difficult to explain how enhanced creativity or innovation can lead to a feeling of routinization. However, it is possible that the relationships between these self-report variables are due to third variables. The relationship between routinization and creative and proactive behaviors might be explained by general self-esteem or self-efficacy. However, Verplanken and Orbell (2003) provide evidence of validity for the habit strength scale. For example, the measure of habit strength correlated with behavioral frequency greater than $r=0.55$ in two studies, and the reported habit strength was greater for daily than for weekly habits. It is hard to explain how these results would occur if the scale measured general self-esteem or self-efficacy. Thus, we feel that this explanation does not apply here.

It might also be that the relationship between routinization on the one hand and self-rated creative and proactive behaviors on the other hand are inflated by a common source bias. However, many of the sources for common method variance listed by Podsakoff and colleagues (2003) do not seem to apply here. For example, routinization and creative and proactive behaviors were measured on different scales with different answering formats. Furthermore, it is unlikely that respondents had implicit theories about the relationship between routinization and creative and proactive behaviors. The different levels of measurement routinization was measured on the task level, and creative and proactive behaviors were measured on a more general level reduce the likelihood of a consistency effect. Controlling for the tendency to give inflated ratings did not change the pattern of relationships between routinization and creative outcomes. Therefore, we feel that we can also rule out effects of social desirability and of positive versus negative affect when making the ratings. Thus, some of the most important sources of common method variance seem unlikely as explanations for the positive relationship between routinization and the creative and proactive behaviors. The validity of curvilinear relationships for time pressure and creativity and innovation might be less constricted. While it is plausible to explain that more creative and innovative behavior leads to more time pressure (upward part of the relationship), it is less plausible to explain how less creative or innovative behavior causes increasingly high time pressure (Janssen, 2001). Though we feel that common method variance can be ruled out to a large extent as an explanation for our results, research using multiple sources of data (observer, supervisor) is needed.

Another limitation of this study is that the sample was drawn from a single company. Though it is a strength that the sample was randomly drawn from all employees of the organizational site, findings are necessarily specific to the setting in which the study was conducted. In particular, the finding that supervisor support is negatively related to number of suggestions made should be treated with caution before it has been replicated in a different study setting.

\section{Implications for practice and research}

The positive relationships between routinization, creativity, and innovation might also explain why formalization, as a potential predictor of routinization, was essentially unrelated to innovation in earlier meta-analytic research (Damanpour, 1991). When routinization results from formalization of work procedures, this might have beneficial effects as discussed above. But when formalization does not result in routinization that frees up resources, it might be that rigid thinking inhibits creativity and innovation, as expected by Pierce and Delbecq (1977). This argument might explain why, in more recent studies, formalization is sometimes positively associated with innovation (Mellor \& Mathieu, 1999; Cardinal, 2001; Johnson et al., 1997; Andrews \& Smith, 1996). One could argue, however, that it is also necessary to distinguish between different tasks or levels where routinization occurs. When one 
task is routinized, the employee might not come up with new ideas to work on this specific task. Thus, routinization might have different effects, depending on the task or outcome examined. Future research will need to differentiate which tasks were routinized and for which tasks ideas were developed and implemented. Experience sampling could be used to collect incidents of individuals having creative ideas, and having individuals rating the degree of routinization in the task they were working on at this very moment. By having experts judge the creativity of the idea and its relationship to the specific task, the question of whether routinization is beneficial for creativity can be answered.

Future research should also assess potential moderating factors in the relationship between routinization and creative and proactive behaviors, because resources made available through routinization (time, cognitive resources) are not necessarily invested into developing and implementing ideas. Job involvement (Kanungo, 1982) is a potential moderator of this relationship, because employees who take their work seriously might be more likely to invest available resources into developing ideas (instead of thinking about topics unrelated to work, such as family or leisure activities). Research also needs to establish the causality and the mediators of the relationship between routinization and creative and proactive behaviors, either through longitudinal field research or through experiments. To test the proposed rationale that available cognitive resources are an underlying mediator of the relationship, a dual task paradigm (Procter \& Dutta, 1995) could be used. Participants would work on a task for a number of trials to practice (more trials for stronger routinization, less trials for weaker routinization), and then continue to work on the task either with or without having to complete a secondary task. The secondary task would consume cognitive resources so that the effect of available cognitive resources on a creative outcome (e.g., number of responses to the assignment to develop alternative approaches to the task) could be tested.

Based on the finding of our study that routinization is positively related to creative and proactive behaviors, and assuming that causality will be shown in future studies, we recommend organizing work so that every job contains some tasks that can be routinized after practice ('hierarchically complete'; Hacker, 1998; cf. Frese \& Zapf, 1994). The automaticity involved in routine tasks might promote performance on other tasks that need more cognitive resources, such as the production of novel and useful ideas (i.e., creativity). Thus, even in more complex jobs, such as in research and development or leadership positions, routinized tasks might contribute to improved job performance. When managers have routinized certain tasks, for example preparing for a meeting, they might have cognitive resources and time available to develop their arguments and to come up with novel examples to illustrate their arguments. It is important to note that this recommendation does not mean a relapse into the principles of scientific management (Taylor, 1923). We do not recommend segmenting a job into parts that can all be executed automatically. Rather, there needs to be a good share of tasks where conscious decisionmaking is needed, but also parts that require fewer cognitive resources. Additionally, based on the positive relationships of job control with creative and proactive behaviors, jobs should be designed so that employees can decide how to accomplish their tasks. This recommendation contrasts with principles of lean production, as studies have shown job control to decrease when lean production is introduced (Delbridge, Lowe, \& Oliver, 2000; Parker, 2003).

Related to the argument of designing jobs with an appropriate share of tasks that are routinized, it is important to give employees opportunities to practice. The beneficial effects of routinization can be stressed to make repetition more pleasant for those persons who find it boring, as there seem to be individual differences in how much routine employees enjoy (Oreg, 2003). When stressing the beneficial effect of routines, managers should also make clear that they value creativity and proactivity.

Related to the findings concerning the number of suggestions made, it seems that establishing or maintaining an organizational suggestion system does not only help to collect employees' ideas to improve innovation, but also provides an opportunity for voice that might enhance perceptions of fairness (Avery \& Quinones, 2002). Thus, having a suggestion system might be beneficial because this 
opportunity might also result in satisfaction and commitment, based on perception of procedural justice (Avery \& Quinones, 2002). Future research will need to test if the implementation of a suggestion system results in improved attitudes towards the organization.

\section{Conclusion}

In summary, although some limitations apply to some of the results reported here, the present study is the first to present evidence that routinization are positively related to creativity and innovation, and not negatively as was often assumed (Anderson et al., 2004; Cardinal, 2001; De Jong \& Kemp, 2003; West, 2002). Furthermore, our study supports the view that job control (Amabile, 1988; Oldham \& Cummings, 1996; Zhou, 1998) and an intermediate level of time pressure might be best for creativity (Baer \& Oldham, in press). Future research will need to replicate this relationship and test for causality, but from our results it is clear that the previously proposed opposition of routinization and creativity is misleading.

\section{Acknowledgements}

The study was conducted while Sandra Ohly, Sabine Sonnentag, and Franziska Pluntke were at the Institute of Psychology, University of Braunschweig, Germany. Sabine Sonnentag is now at the Department of Psychology, University of Konstanz. Franziska Pluntke is now at the Department of Business Administration, University of Wuppertal. The paper is based on a part of the dissertation of Sandra Ohly. We thank William Greeene and Jürgen Meinecke for their help in data analysis issues, David Holman, Charlotte Fritz, and Jörg Felfe for helpful comments on an earlier version of this article, and Jennifer McInroe for copyediting the final manuscript.

\section{Author biographies}

Sandra Ohly is a research associate of Industrial and Organizational Psychology and lecturer at the Technical University of Braunschweig, Germany. She obtained her PhD in 2005 from the Technical University of Braunschweig. Her current research interests include voluntary employee behavior targeting change (e.g., creativity, learning and proactive behavior), the effects of time pressure, the role of work routines, and work motivation.

Sabine Sonnentag is a full professor of Work and Organizational Psychology at the University of Konstanz, Germany. In her research she is mainly interested in how individual can achieve sustained high performance at work and remain healthy at the same time. Her major research topics include: (1) performance at work and its relationship to self-regulatory processes, (2) recovery and unwinding from work stress and (3) continuous learning at work.

Franziska Pluntke is a $\mathrm{PhD}$ candidate in Human Resource Management and Organization at the University of Wuppertal, Germany. Her current research interests include the development of new 
ventures and strategies of legitimation, institutional entrepreneurship, assessment of management development and performance appraisal tools.

\section{References}

Aarts, H., \& Dijksterhuis, A. (2000). Habits as knowledge structures: automaticity in goal directed behavior. Journal of Personality and Social Psychology, 78, 5363.

Aiken, M., Bacharach, S. B., \& French, J. L. (1980). Organizational structure, work process, and proposal making in administrative bureaucracies. Academy of Management Journal, 23, 631652.

Amabile, T. M. (1988). A model of creativity and innovation in organizations. In B. M. Staw, \& L. L. Cummings (Eds.), Research in organizational behavior (Vol. 10, pp. 123 167). Greenwich, CT: JAI Press.

Amabile, T. M., Mueller, J. S., Simpson, W. B., Hadley, C. N., Kramer, S. J., \& Fleming, L. (2003). Time pressure and creativity in organizations: a longitudinal field study. Harvard Business School Working Paper.

Anderson, J. R. (2000). Cognitive psychology and its implications (5th ed.). New York, NY: Worth Publishers.

Anderson, N., De Dreu, C. K. W., \& Nijstad, B. A. (2004). The routinization of innovation research: a constructively critical review of the state of the science. Journal of Organizational Behavior, 25, 147173.

Andrews, J., \& Smith, D. C. (1996). In search of the marketing imagination: factors affecting the creativity of marketing programs for mature products. Journal of Marketing Research, 33, 174187.

Avery, D. R., \& Quinones, M. A. (2002). Disentangling the effects of voice: the incremental roles of opportunity, behavior, and instrumentality in predicting procedural fairness. Journal of Applied Psychology, $87,8186$.

Axtell, C. M., Holman, D. J., Unsworth, K. L., Wall, T. D., \& Waterson, P. E. (2000). Shopfloor innovation: facilitating the suggestion and implementation of ideas. Journal of Occupational and Organizational Psychol ogy, 73, 265285.

Baba, V. V., \& Jamal, M. (1991). Routinization in job context and job content as related to employees' quality of working life: a study of Canadian nurses. Journal of Organizational Behavior, 12, 379386.

Baer, M., \& Oldham, G. R. (in press). The curvilinear relation between experienced creative time pressure and creativity: moderating effects of support, support for creativity and openness to experience. Journal of Applied Psychology.

Bargh, J. A. (1994). The four horsemen of automaticity: awareness, intention, efficiency, and control in social cognition. In R. S. j. Wyer, \& T. K. Srull (Eds.), Handbook of social cognition (2nd ed., Vol. 1, pp. 1 40). Hillsdale, NJ: Lawrence Erlbaum Associates.

Bargh, J. A., \& Barndollar, K. (1996). Automaticity in action: the unconscious as repository of chronic goals and motives. In P. M. Gollwitzer, \& J. A. Bargh (Eds.), The psychology of action: Linking cognition and motivation to behavior (pp. 457 481). New York, NY: The Guilford press.

Betsch, T., Haberich, S., Glöckner, A., Haar, T., \& Fiedler, K. (2001). The effects of routine strength on adaptation and information search in recurrent decision making. Organizational Behavior and Human Decision Making Processes, 84, 2353.

Cardinal, L. B. (2001). Technological innovation in the pharmaceutical industry: the use of organizational control in managing research and development. Organization Science, 12, 1936.

Clegg, C., Unsworth, K., Epitropaki, O., \& Parker, G. (2002). Implicating trust in the innovation process. Journal of Occupational and Organizational Psychology, 75, 409422.

Cohen, J., Cohen, P., West, S. G., \& Aiken, L. S. (2003). Applied multiple regression/correlation analysis for the behavioral sciences. Mahwah, NJ: Lawrence Erlbaum Associates.

Damanpour, F. (1991). Organizational innovation: a meta analysis of effects of determinants and moderators. Academy of Management Journal, 34, 555590.

De Jong, J. P. J., \& Kemp, R. (2003). Determinants of co workers innovative behaviour: an investigation into knowledge intensive services. International Journal of Innovation Management, 7, 189212.

de Lange, A. H., Taris, T. W., Kompier, M. A. J., Houtman, I. L. D., \& Bongers, P. M. (2003). "The very best of the millennium": longitudinal research and the demand control (support) model. Journal of Occupational Health Psychology, 8, 282305. 
Delbridge, R., Lowe, J., \& Oliver, N. (2000). Shopfloor responsibilities under lean teamworking. Human Relations, 53, 14591479.

Dietz, J., Robinson, S. L., Folger, R., Baron, R. A., \& Schulz, M. (2003). The impact of community violence and an organization's procedural justice climate on workplace aggression. Academy of Management Journal, 46, 317 326.

Ekvall, G. ( 1971). Creativity at the place of work: A study of suggestors and suggestion systems in the Swedish mechanical industry. Stockholm: The Swedish council for personnel administration.

Fay, D., \& Sonnentag, S. (2002). Rethinking the effects of stressors: a longitudinal study on personal initiative. Journal of Occupational Health Psychology, 7, 221234.

Ford, C. M., \& Gioia, D. A. (2000). Factors influencing creativity in the domain of managerial decision making. Journal of Management, 26, 705732.

Frese, M., \& Fay, D. (2001). Personal initiative: an active performance concept for work in the 21 st century. In B. M. Staw, \& R. L. Sutton (Eds.), Reserach in organizational behavior (Vol. 23, pp. 133 187). Stamford, CT: JAI Press.

Frese, M., Fay, D., Hilburger, T., Leng, K., \& Tag, A. (1997). The concept of personal initiative: operationalization, reliability and validity in two German samples. Journal of Occupational and Organizational Psychology, 70, 139161.

Frese, M., Kring, W., Soose, A., \& Zempel, J. (1996). Personal initiative at work: differences between East and West Germany. Academy of Management Journal, 39, 3763.

Frese, M., Teng, E., \& Wijnen, C. J. D. (1999). Helping to improve suggestion systems: predictors of making suggestions in companies. Journal of Organizational Behavior, 20, 11391155.

Frese, M., \& Zapf, D. (1994). Action as the core of work psychology: a German approach. In H. C. Triandis, M. D. Dunnette, \& L. M. Hough (Eds.), Handbook of industrial and organizational psychology (2nd ed., Vol. 4, pp. 271 340). Palo Alto, CA: Consulting Psychologist Press.

Gardner, D. G. (1986). Activation theory and task design: an empirical test of several new predictions. Journal of Applied Psychology, 71, 411418.

Gardner, W., Mulvey, E. P., \& Shaw, E. C. (1995). Regression analyses of counts and rates: Poisson, overdispersed Poisson, and negative binomial models. Psychological Bulletin, 118, 392404.

Gebert, D., Boerner, S., \& Lanwehr, R. (2003). The risks of autonomy: empirical evidence for the necessity of a balance management in promoting organizational innovativeness. Creativity and Innovation Management, 12, 4149.

Gilson, L. L., Mathieu, J. E., Shalley, C. E., \& Ruddy, T. M. (in press). Creativity and standardization: complementary or conflicting drivers of team effectiveness. Academy of Management Journal.

Gilson, L. L., \& Shalley, C. E. (2004). A little creativity goes a long way: an examination of teams' engagement in creative processes. Journal of Management, 30, 435470.

Grebner, S., Semmer, N. K., \& Elfering, A. (2005). Working conditions and three types of well being: a longitudinal study with self report and rating data. Journal of Occupational Health Psychology, 10, 3143.

Hacker, W. (1998). Allgemeine Arbeitspsychologie [General work psychology]. Bern: Verlag Hans Huber.

Hackman, R., \& Oldham, G. R. (1975). Development of the job diagnostic survey. Journal of Applied Psychology, $60,159170$.

Janssen, O. (2001). Fairness perceptions as a moderator in the curvilinear relationships between job demands, and job performance and job satisfaction. Academy of Management Journal, 44, 10391050.

Johnson, J. D., Meyer, M. E., Berkowitz, J. M., Ethington, C. T., \& Miller, V. D. (1997). Testing two contrasting structural models of innovativeness in a contractual network. Human Communication Research, 24, 320348.

Kanfer, R., \& Ackerman, P. L. (1989). Motivation and cognitive abilities: an integrative/aptitude treatment interaction approach to skill acquisition. Journal of Applied Psychology, 74, 657690.

Kanungo, R. N. (1982). Measurement of job and work involvement. Journal of Applied Psychology, 3, 341349.

LePine, J. A., \& Van Dyne, L. (1998). Predicting voice behavior in work groups. Journal of Applied Psychology, 83, 853868.

Norman, D. A., \& Bobrow, D. G. (1975). On data limited and resource limited processes. Cognitive Psychology, 7 , 4464.

Madjar, N., Oldham, G. R., \& Pratt, M. G. (2002). There's no place like home? The contributions of work and nonwork creativity support to employees' creative performance. Academy of Management Journal, 45, 757 767. 
Mellor, S., \& Mathieu, J. E. (1999). A discriminant validity study of aggregate level constructs and measures of local union formalization, centralization, and innovation. The Journal of Psychology, 133, 669683.

Oldham, G. R., \& Cummings, A. (1996). Employee creativity: personal and contextual factors at work. Academy of Management Journal, 39, 607634.

Oreg, S. (2003). Resistance to change: developing an individual difference measure. Journal of Applied Psychology, 88, 680693.

Ouellette, J. A., \& Wood, W. (1998). Habit and intention in everyday life: the multiple processes by which past behavior predicts future behavior. Psychological Bulletin, 124, 5474.

Parker, S. K. (2003). Longitudinal effects of lean production on employee outcomes and the mediating role of work characteristics. Journal of Applied Psychology, 88, 620634.

Parker, S. K., \& Sprigg, C. A. (1999). Minimizing strain and maximizing learning: the role of job demands, job control, and proactive personality. Journal of Applied Psychology, 84, 925939.

Perrow, C. (1970). Organizational analysis: A sociological view. Belmont, CA: Brooks/Cole Publishing Company.

Pierce, J. L., \& Delbecq, A. L. (1977). Organizational structure, individual attitudes and innovation. Academy of Management Review, 2, 2737.

Podsakoff, P. M., MacKenzie, S. B., Lee, J. Y., \& Podsakoff, N. (2003). Common method biases in behavioral research: a critical review of the literature and recommended remedies. Journal of Applied Psychology, 88, 879 903.

Price, J. L., \& Mueller, C. W. (1981). A causal model of turnover for nurses. Academy of Management Journal, 24, 543565.

Procter, R. W., \& Dutta, A. (1995). Skill development and human performance. Thousand Oaks, CA: Sage.

Rank, J., Pace, V. L., \& Frese, M. (2004). Three avenues for future research on creativity, innovation, and initiative. Applied Psychology: An International Review, 53, 518528.

Scott, W. E. J. (1966). Activation theory and task design. Organizational Behavior and Human Performance, 1, 330 .

Scott, S. G., \& Bruce, R. A. (1994). Determinants of innovative behavior: a path model of individual innovation in the workplace. Academy of Management Journal, 37, 580607.

Semmer, N. (1984). Stressbezogene Tatigkeitsanalyse: Psychologische Untersuchungen zur Analyse von Stress am Arbeitsplatz. Weinheim: Beltz.

Semmer, N., \& Zapf, D. (1989). Validity of various methods of measurement in job analysis. In K. Landau, \& W. Rohmert (Eds.), Recent developments in job analysis (pp. 67 78). London: Taylor \& Francis.

Semmer, N., Zapf, D., \& Dunckel, H. (1999). Instrument zur Stressbezogenen Tätigkeitsanalyse. In H. Dunckel (Ed.), Handbuch psychologischer Arbeitsanalyseverfahren (pp. 179 204). Zürich: vdf Hochschulverlag an der ETH.

Shalley, C. E. (1991). Effects of productivity goals, creativity goals, and personal discretion on individual creativity. Journal of Applied Psychology, 76, 179185.

Shalley, C. E., \& Perry Smith, J. E. (2001). Effects of social psychological factors on creative performance: the role of informational and controlling expected evaluation and modeling experience. Organizational Behavior and Human Decision Processes, 84, 122.

Shiffrin, R. M., \& Schneider, W. (1977). Controlled and automatic human information processing: II Perceptual learning, automatic attending and a general theory. Psychological review, 84, 127190.

Sonnentag, S. (2003). Recovery, work engagement, and proactive behavior: a new look at the interface between nonwork and work. Journal of Applied Psychology, 88, 518528.

Taylor, F. W. (1923). The principles of scientific management. New York, NY: Harper.

Tierney, P., \& Farmer, S. M. (2002). Creative self efficacy: it potential antecedents and relationship to creative performance. Academy of Management Journal, 45, 11371148.

Tierney, P., Farmer, S. M., \& Graen, G. B. (1999). An examination of leadership and employee creativity: the relevance of traits and relationships. Personnel Psychology, 52, 591620.

Unsworth, K. L., \& Parker, S. K. (2003). Proactivity and innovation: promoting a new workforce for the new workplace. In D. J. Holman, T. D. Wall, C. W. Clegg, P. Sparrow, \& A. Howard (Eds.), The new workplace (pp. 175 196). Chichester: Wiley.

Van Dyne, L., Ang, S., \& Botero, I. C. (2003). Conceptualizing employee silence and employee voice as multidimensional constructs. Journal of Management Studies, 40, 13591392.

VanLehn, K. (1996). Cognitive skill acquisition. Annual Review of Psychology, 47, 513539.

Verplanken, B., \& Orbell, S. (2003). Reflections on past behavior: a self report index of habit strength. Journal of Applied Social Psychology, 33, 13131330. 
Weiss, H. M., \& Ilgen, D. R. (1985). Routinized behavior in organizations. Journal of Behavioral Economics, 14, 5767.

Wickens, C. D., \& Hollands, J. G. (2000). Engineering psychology and human performance (3rd ed.). Upper Saddle River, N. J.: Prentice Hall.

West, M. A. (2002). Sparkling fountains or stagnant ponds: an integrative model of creativity and innovation implementation in work groups. Applied Psychology: An International Review, 51, 355424.

Zapf, D. (1993). Stress oriented analysis of computerized office work. European Work and Organizational Psychologist, 37, 85100.

Zhou, J. (1998). Feedback valence, feedback style, task autonomy, and achievement orientation: interactive effects on creative performance. Journal of Applied Psychology, 83, 261276.

Zhou, J., \& George, J. M. (2001). When job dissatisfaction leads to creativity: encouraging the expression of voice. Academy of Management Journal, 44, 682696. 